\title{
Thymoquinone hydrazone derivatives cause cell cycle arrest in p53-competent colorectal cancer cells
}

\author{
ANDRÉ WIRRIES $^{1}$, SANDRA BREYER $^{2}$, KARL QUINT $^{1,3}$, RAINER SCHOBERT $^{2}$ and MATTHIAS OCKER MA $^{1,3}$ \\ ${ }^{1}$ Department of Medicine 1, University Hospital Erlangen, 91054 Erlangen; ${ }^{2}$ Organic Chemistry Laboratory, University of \\ Bayreuth, 95440 Bayreuth; ${ }^{3}$ Institute for Surgical Research, Philipps-University Marburg, 35043 Marburg, Germany
}

Received November 3, 2009; Accepted December 8, 2009

DOI: 10.3892/etm_00000058

\begin{abstract}
Thymoquinone (TQ), the major compound of black seed oil, has been shown to induce pro-apoptotic signaling pathways in various human cancer models. Although TQ is commonly used in traditional medicine, its use in humans is limited due to its chemical properties and poor membrane penetration capacity. We therefore attached saturated and unsaturated fatty acid residues to TQ and evaluated the effect on cell proliferation, apoptosis and underlying signaling pathways in HCT116 and HCT116 colon cancer and HepG2 hepatoma cells in vitro. Treatment with thymoquinone-4- $\alpha$-linolenoylhydrazone (TQ-H-10) or thymoquinone-4-palmitoylhydrazone (TQ-H-11) induced a cytostatic effect, particularly in p53-competent HCT116 cells, mediated by an up-regulation of $21^{\mathrm{cip} 1 / \mathrm{waf} 1}$ and a down-regulation of cyclin $\mathrm{E}$, and associated with an $\mathrm{S} / \mathrm{G}_{2}$ arrest of the cell cycle. Cells lacking p53 (HCT116 (H3-/-) $^{\text {) }}$ or HepG2 liver cancer cells showed only a minor response to TQ-H-10. These findings demonstrate that derivatives of TQ inhibit cell proliferation dependent on p53 status by activating the cell cycle inhibitor $\mathrm{p} 21^{\text {cip1/waf1 }}$ at lower concentrations than unmodified TQ. Structural modifications can therefore contribute to the further clinical development of TQ.
\end{abstract}

\section{Introduction}

Colorectal cancer still represents a major medical challenge. Besides improving current available therapies, new treatment methods must be evaluated in order to provide improved outcomes for patients with advanced stages of the disease. A variety of plant-derived drugs have recently been explored for anticancer efficacy (1). It has been demonstrated that thymoquinone (TQ), which is the major compound of black seed (Nigella sativa) oil, traditionally used in Mediterranean

Correspondence to: Dr Matthias Ocker, Institute for Surgical Research, Philipps-University Marburg, Baldingerstrasse, 35043 Marburg, Germany

E-mail: matthias.ocker@staff.uni-marburg.de

Key words: thymoquinone, cell cycle, cyclin E and Arab medicine, possesses significant anticancer effects in various cancer models (2).

We previously showed that TQ induces apoptosis through p53-dependent pathways in human colon cancer cells and animal models $(3,4)$. Although $\mathrm{LD}_{50}$ values for TQ in mice and rats indicate that high doses are tolerable in vivo (5), the high concentrations required impair these positive effects. In addition, due to its chemical structure (2-isopropyl-5methylbenzo-1,4-quinone), TQ is unstable under physiologic conditions and in aqueous solutions, and shows only a low capacity to penetrate through biologic membranes. Recently, we demonstrated that the chemical modification of TQ by attachment of saturated and unsaturated fatty acid side chains enhanced the biological efficacy of TQ by increasing ROS production and inducing apoptosis in HL-60 leukaemia and 518A2 melanoma cells (6). Besides having a cytotoxic effect, TQ has been demonstrated to interfere with the cell cycle by inhibiting the activity of polo-like kinase 1 (PLK1), which is a key regulator of mitosis progression and is itself regulated by p53 (7).

Based on these findings, we developed further TQ derivatives which, in the present study, were investigated for their cell cycle regulating activity in HCT116 colon cancer cells and the human hepatoma cell line HepG2. Dependent on p53 status, these new molecules induced a cytostatic effect at low concentrations by the up-regulation of $\mathrm{p} 21^{\text {cip1/waf } 1}$ and the suppression of cyclin E.

\section{Materials and methods}

Design and synthesis of thymoquinone derivatives. The thymoquinone hydrazones (TQ-H) were prepared from TQ and $\alpha$-linolenic acid or hexadecanoic acid, respectively, according to a previously applied general procedure (6).

Cell growth and treatment. Human HCT116 colon cancer cells (wild-type and derivatives lacking p53) and human HepG2 hepatocellular carcinoma cells were cultivated in RPMI-1640 medium supplemented with $10 \%$ fetal bovine serum (FBS), $1 \%$ penicillin and $0.5 \%$ streptomycin in an atmosphere of $5 \% \mathrm{CO}_{2}$ at $37^{\circ} \mathrm{C}$. Cell cultures were grown on Nunc EasyFlasks (Thermo Fisher Scientific, Roskilde, Denmark). Cell culture media and supplements were obtained from Biochrom, Berlin, Germany. Cell lines were obtained from the German Collection of Microorganisms and Cell Cultures 
Table I. Western blot antibodies.

\begin{tabular}{llr}
\hline Antigen & Manufacturer; Dilution & Second antibody; Dilution \\
\hline p21 & & Mouse, 1:1000 \\
p53 & BD Bioscience, mouse monoclonal; 1:500 & Mouse; 1:1000 \\
Cyclin A & BD Bioscience, mouse monoclonal; 1:500 & Mouse; 1:1000 \\
Cyclin D & Abcam, mouse monoclonal; 1:500 & Rabbit; 1:1000 \\
Cyclin E & Abcam, rabbit monoclonal; 1:200 & Rabbit; 1:1000 \\
$\beta$-actin & Abcam, rabbit polyclonal; 1:200 & Mouse; $1: 1000$ \\
\hline
\end{tabular}

(DSMZ, Braunschweig, Germany); HCT116 ${ }^{\text {p53-- }}$ cells were a gift from B. Vogelstein (Johns Hopkins University, Baltimore, MD, USA).

For $24-72 \mathrm{~h}$ of treatment, $10^{5}$ or $5 \times 10^{4}$ cells were seeded in 6 -well plates and allowed to adhere overnight. TQ derivatives were added at different concentrations $(0.01-10 \mu \mathrm{M})$ for the indicated time points.

Cell number and cell cycle analysis. Treated cells were washed with phosphate-buffered saline (PBS; Biochrom) and lysed by incubation with trypsin/EDTA (Biochrom). Cell number was determined by counting the viable cells after trypan blue staining in a Neubauer chamber as described previously (8). Apoptosis and DNA content were determined by flow cytometry on a FACSCalibur fluorescence activated cell sorter (BD Bioscience, Heidelberg, Germany) after staining with hypotonic propidium iodide solution $(0.1 \%$ sodium citrate, $0.1 \%$ Triton $\mathrm{X}-100$ and $50 \mu \mathrm{g} / \mathrm{ml}$ propidium iodide; all from Sigma, Deisenhofen, Germany) as described previously (8). For each sample, 10,000 events were collected, and the percentage of cells with a subdiploid DNA content in different phases of the cell cycle was determined using CellQuest software (BD Bioscience). Results displayed in the graphs and diagrams are the mean and standard deviation of three independent experiments.

Protein extraction and Western blot analysis. Total protein was extracted after treatment under the indicated conditions using Jie's protein extraction buffer as described previously (9). Proteins were quantified using the Pierce BCA Protein Assay kit (Thermo Scientific, Rockford, IL, USA) according to the manufacturer's protocol. Samples were subjected to gel electrophoresis on NuPAGE Bis-Tris Gels (Invitrogen, Carlsbad, CA, USA) for $50 \mathrm{~min}$ at $200 \mathrm{~V}$ and $125 \mathrm{~mA}$. Proteins were then transferred to a nitrocellulose transfer membrane (Whatman, Dassel, Germany) at $90 \mathrm{~V}$ for $30 \mathrm{~min}$. Membranes were blocked at $4^{\circ} \mathrm{C}$ overnight using PBS with $0.1 \%$ Tween-20 and $5 \%$ low fat milk powder, and then probed with primary antibodies (Table I) for $90 \mathrm{~min}$ at room temperature (RT). Membranes were washed three times with blocking buffer and incubated with appropriate secondary antibodies for $1 \mathrm{~h}$ at RT (Table I). Reactive bands were visualized using enhanced chemiluminescence (ECL) and exposure to X-ray films. Densitometry analysis was performed using GelScan 5 software (BioSciTec, Frankfurt, Germany). All membranes were stripped with glycine-buffer ( $\mathrm{pH}$ 2.0) and reprobed with an anti- $\beta$-actin antibody to show equal loading of the lanes.

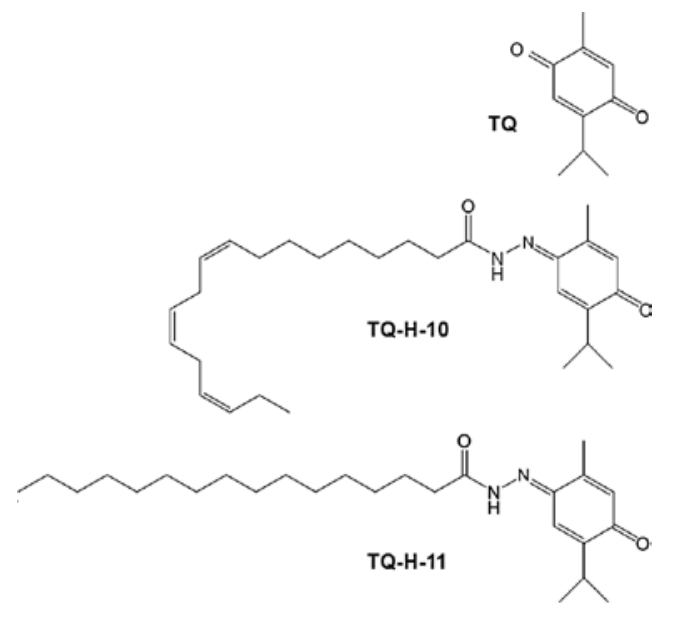

Figure 1. Chemical structures of thymoquinone (TQ) and the thymoquinone hydrazone derivatives used for treatment.

RNA extraction, cDNA synthesis and quantitative real-time $P C R$. Total RNA was extracted using peqGOLD RNA Pure (Peqlab, Erlangen, Germany) according to the manufacturer's instructions. cDNA synthesis was performed as described previously using oligo(dT)15 primer and random hexamer primer (both from Promega, Mannheim, Germany) with $100 \mathrm{U}$ SuperScript II reverse transcriptase (Invitrogen). Relative transcript levels were quantified by real-time RT-PCR using $2 \mu \mathrm{l}$ of template cDNA on a thermal cycler system (CFX96 Real Time System, C1000 Thermal Cycler; BioRad). Quantitect Primers for human CCNA2, CCND2, CCNE2, TP53, CDKN1A as well as GAPDH were obtained from Qiagen (Hilden, Germany). PCR was performed with the Absolute SYBR Green Fluorescein Mix (Thermo Scientific, ABgene House, Epsom, Surrey, UK) according to the manufacturer's instructions. Data were analyzed with Bio-Rad CFX Manager software. Results were normalized to GAPDH levels. Samples were analyzed in duplicate.

Statistical analysis. Significance was calculated using the t-test for paired samples. $\mathrm{P}<0.05$ was regarded as significant.

\section{Results}

Thymoquinone hydrazone derivatives inhibit proliferation of human colon cancer cells in vitro. Human HCT116 colon cancer cells and the derivative lacking p53 (HCT116 ${ }^{\mathrm{p} 53-/-}$ ), as 
$\mathbf{A}$

TQ-H-10

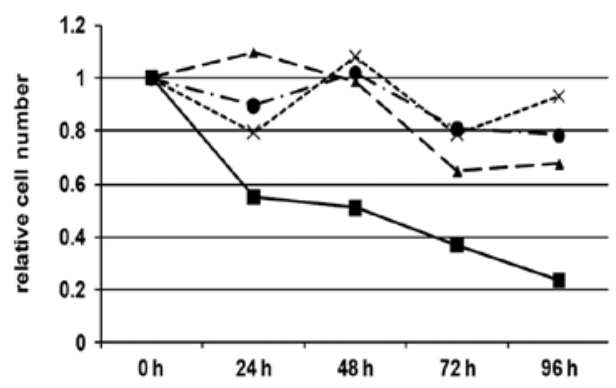

B

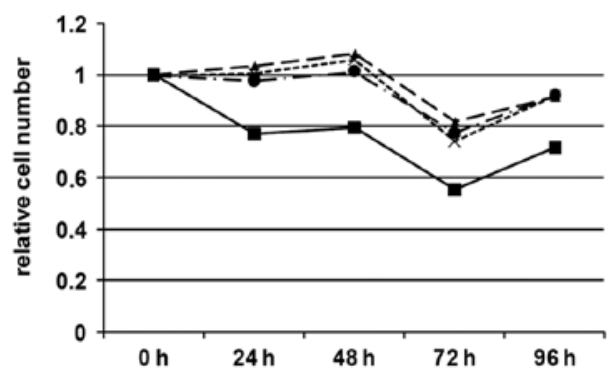

C

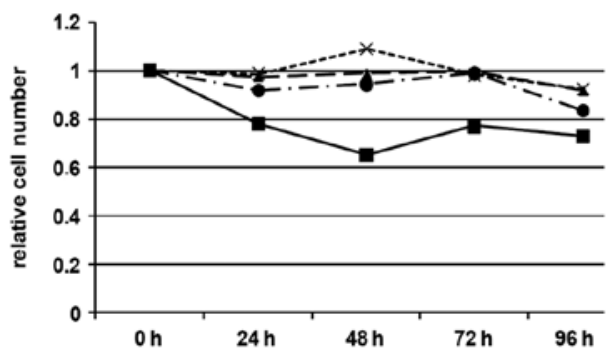

D

TQ-H-11

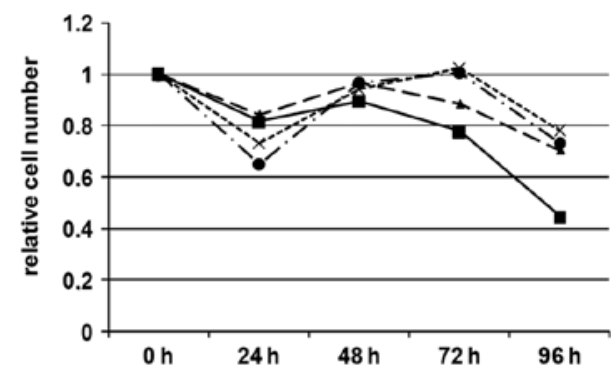

E

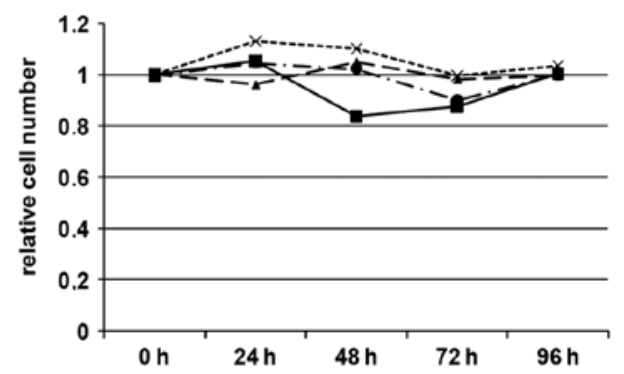

$\mathbf{F}$

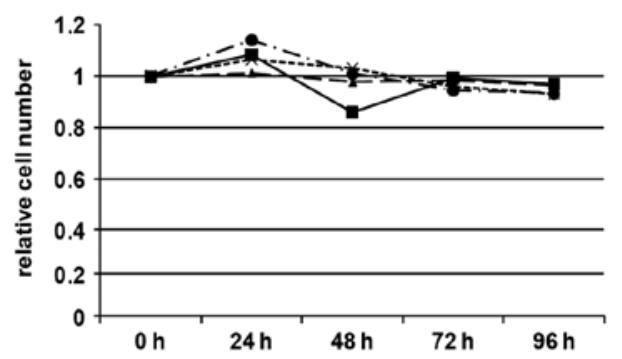

$10 \mu \mathrm{M} \quad-\Delta-1 \mu \mathrm{M}$

$0.1 \mu \mathrm{M} \quad \nsim 0.01 \mu \mathrm{M}$

Figure 2. Cell counts of viable cells after 24-96 h of treatment with different thymoquinone hydrazone derivatives. The HCT116 (A and D), HCT-116 ${ }^{\mathrm{p} 33-1-}$ (B and E) and HepG2 (C and F) cell lines are shown according to treatment with 0.01-10 $\mu \mathrm{M}$ thymoquinone hydrazone derivatives (TQ-H-10: A-C; TQ-H-11: D-F). Each graph shows one cell line treated with one derivative according to the duration of treatment, expressed relative to an untreated control. Controls are set as 1.0 at every time point and are not shown separately. Results are the mean of three independent experiments.

well as the human HepG2 liver cancer cell line, were exposed to different concentrations of thymoquinone hydrazone derivatives (TQ-H) for 24-96 $\mathrm{h}$ at concentrations of 0.1 to $10 \mu \mathrm{M}$, thus not exceeding cytotoxic doses $\left(\mathrm{IC}_{50}, 40 \mu \mathrm{M}\right)$, as reported previously (10). As shown in Fig. 2, the viable cell count revealed significant effects of the two investigated TQ-H derivatives.

HCT116 cells proved to be most sensitive to treatment with either thymoquinone-4- $\alpha$-linolenoylhydrazone (TQ-H-10) or thymoquinone-4-palmitoylhydrazone (TQ-H-11) (Fig. 2A and D). At $10 \mu \mathrm{M}$, both compounds significantly decreased the number of viable cells to $24 \%$ of the untreated controls for TQ-H-10 and 45\% for TQ-H-11 after $96 \mathrm{~h}$. Lower concentrations also reduced cell proliferation in this cell line to 65 and $80 \%$ at 1 and $0.1 \mu \mathrm{M}$, respectively, for TQ-H-10, and to $\sim 75 \%$ for TQ-H-11. In contrast, reduction in cell proliferation was less pronounced for HCT116 $6^{\text {p33-- }}$ cells (Fig. 2B and E). In these cells, only $10 \mu \mathrm{M}$ of TQ-H-10 led to a decrease in cell number of $\sim 58 \%$ after $72 \mathrm{~h}$ and $72 \%$ after $96 \mathrm{~h}$; lower concentrations of TQ-H-10 did not affect cell proliferation. Surprisingly, TQ-H-11 was ineffective even at $10 \mu \mathrm{M}$. A similar pattern was observed for the human HepG2 liver cancer cell line (Fig. 2C and F). Only $10 \mu \mathrm{M}$ of TQ-H-10 led to a significant decrease in cell number at $48-96 \mathrm{~h}$, ranging from 65 to $75 \%$ of the untreated controls. Lower concentrations of TQ-H-10 as well as all tested concentrations of TQ-H-11 were ineffective.

TQ-H derivatives induce changes in the distribution of cell cycle phases. Cell cycle distribution and apoptosis were determined by flow cytometry after propidium iodide staining. In parallel to cell counting experiments, HCT116 cells proved to be most sensitive to treatment with $10 \mu \mathrm{M}$ TQ-H-10 or TQ-H-11 (Fig. 3A and D). Both compounds induced a significant shift in the cell cycle distribution towards the $\mathrm{S} /$ $\mathrm{G}_{2}$ phase after 72 and $96 \mathrm{~h}$. In detail, the amount of cells in the $\mathrm{S} / \mathrm{G}_{2}$ phase increased from 67.8 to $89.1 \%$ and from 62.4 to $88.6 \%$ after 72 or $96 \mathrm{~h}$ of treatment with TQ-H-10. TQ-H-11 increased this parameter from 72.3 to $88.1 \%$ and from 49.2 to $84.5 \%$, respectively. Representative flow cytometry scans are shown in Fig. 4. Similar to the results described above, neither TQ-H-10 nor TQ-H-11 influenced the distribution of the cell cycle at $10 \mu \mathrm{M}$ in either the HCT116 $6^{\text {p53-- }}$ (Fig. 3B and C) or HepG2 cells (Fig. 3E and F). 
A

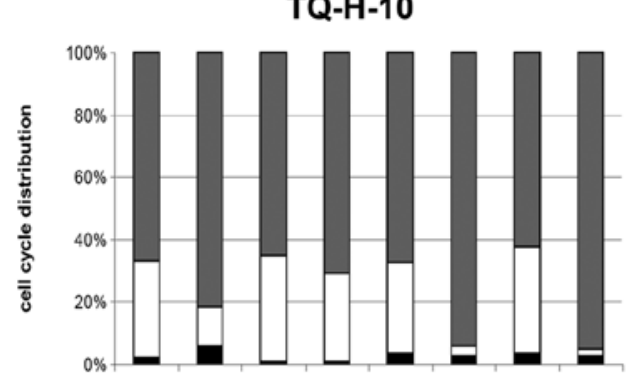

B

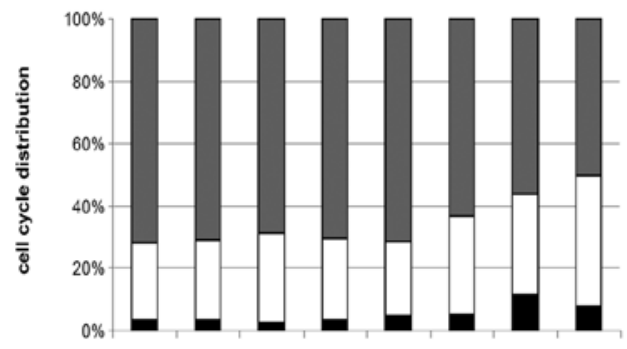

C

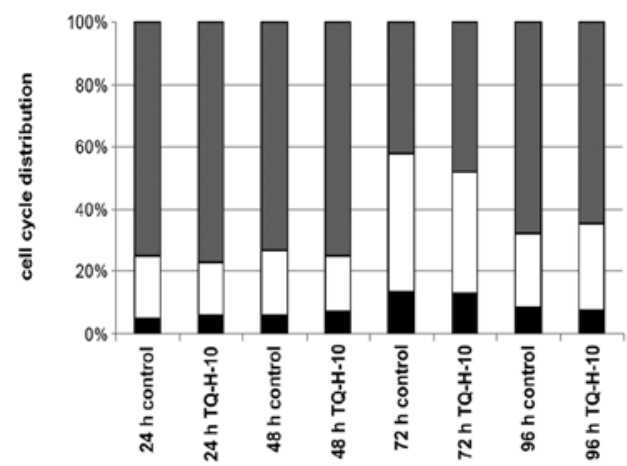

D

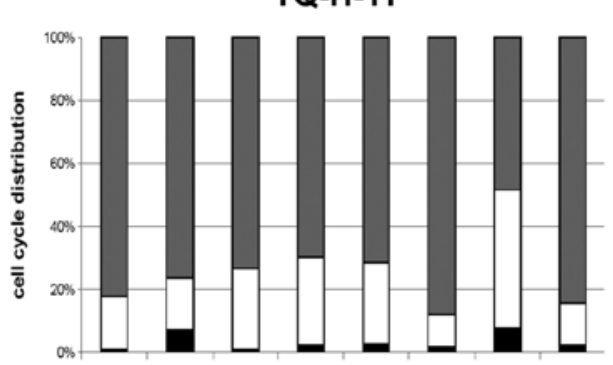

E

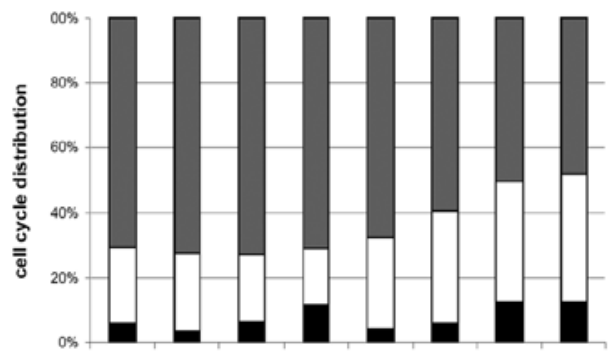

$\mathbf{F}$

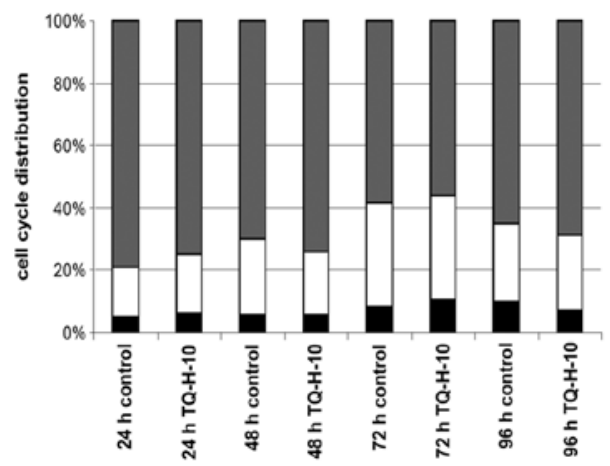

- Apoptosis $\square G_{1} \quad \square S / G_{2}$

Figure 3. Relative distribution of cell cycle phases in each cell line and treatment according to flow cytometry. Distribution of cell cycle phases was scored

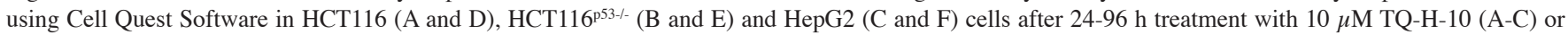
TQ-H-11 (D-F). Results are the mean of three independent experiments.

A

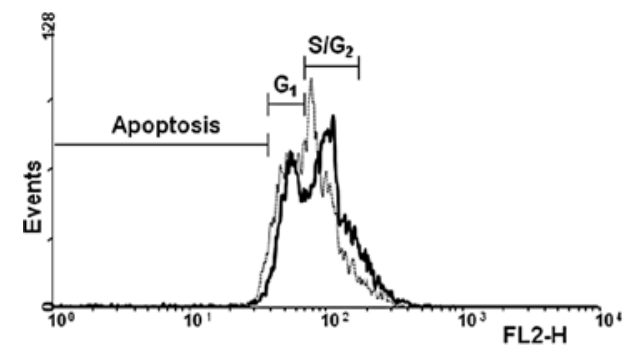

B

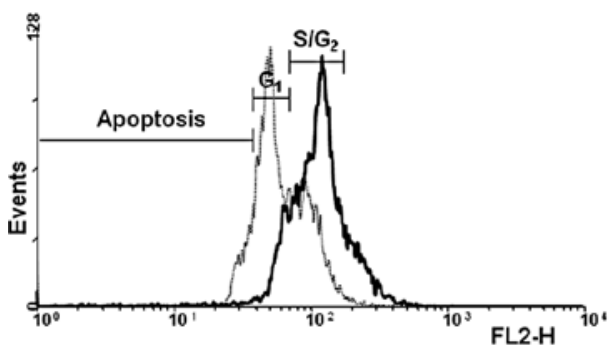

C

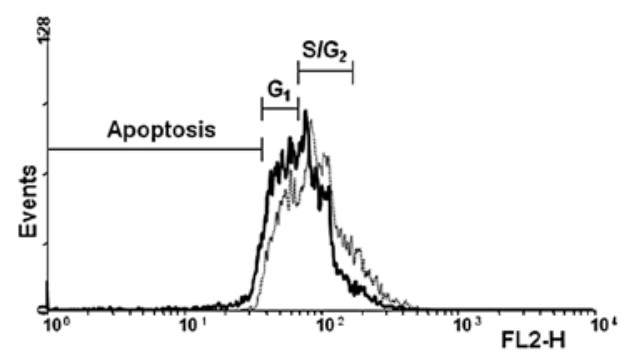

D

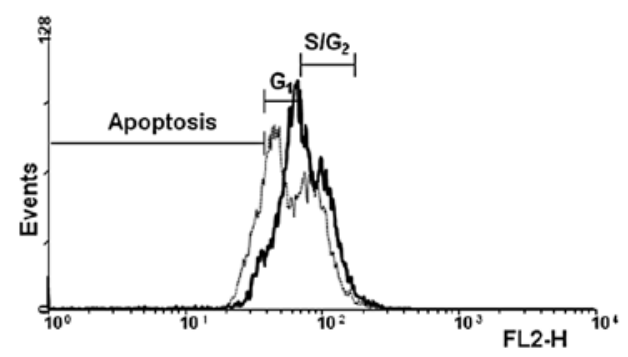

Figure 4. Representative flow cytometry histograms of HCT116 cells treated with TQ-H-10 or TQ-H-11. Cells were treated for $48 \mathrm{~h}$ (A and C) or $72 \mathrm{~h}$ (B and D) with $10 \mu \mathrm{M}$ of TQ-H-10 (A and B) and TQ-H-11 (C and D). Each graph shows treated cells (10 $\mu \mathrm{M})$ (black line) compared to untreated controls (grey line). Cells treated with TQ-H-10 show a shift in the distribution of cell cycle phases after propidium iodide staining towards more $S / G_{2}$ and less $G_{1}$ phase $(A$ and B) cells. Treatment with TQ-H-11 shows a similar but lesser effect (C and D). No treatment indicates an increase in apoptosis as determined by sub- $\mathrm{G}_{1}$ events. Each analysis was carried out in triplicate. 
A
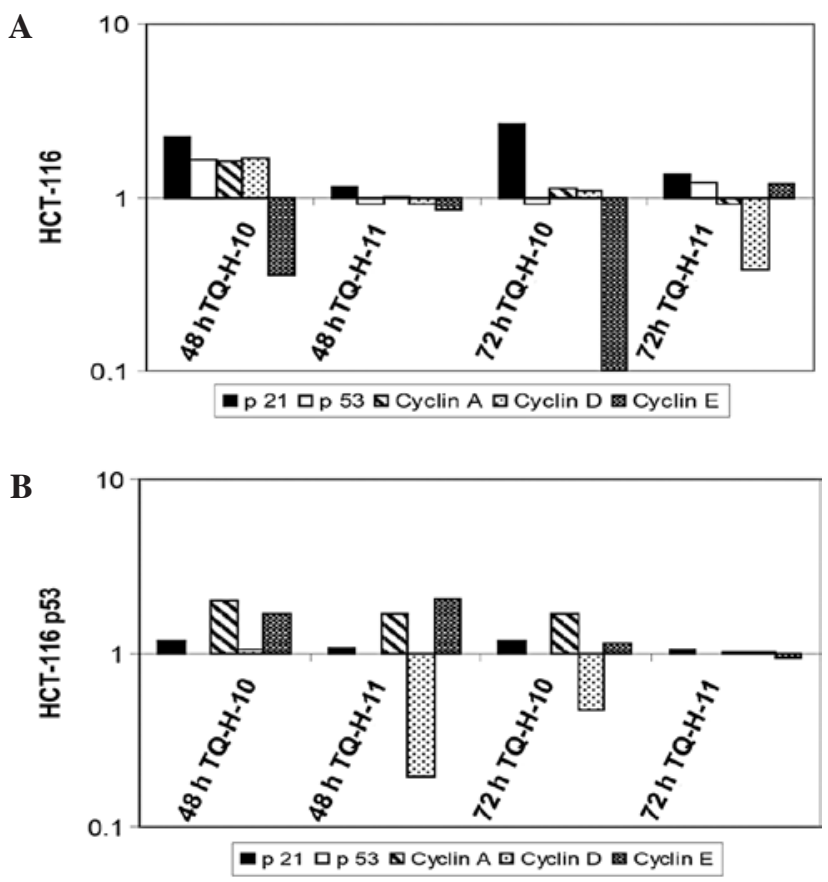

C

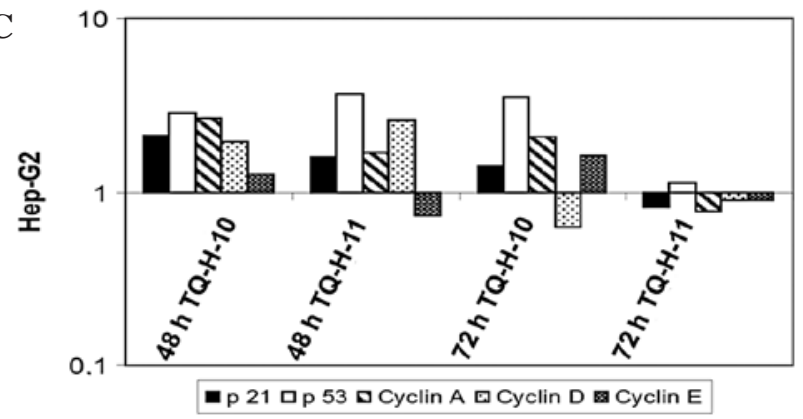

Figure 5. Quantitative real-time PCR of cell cycle-related genes. Shown are the mean mRNA levels of cell cycle-related genes (p21 cip1/wafl,$p 53$ and cyclins A, D and E) after 48 and $72 \mathrm{~h}$ treatment with TQ-H-10 or TQ-H-11 in

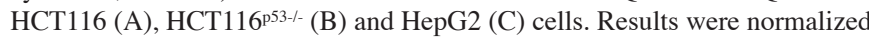
to GAPDH and are expressed relative to untreated controls set at 1.0 .
Molecular analysis of cell cycle regulating factors after $T Q-H$ treatment. To investigate which factors are involved in TQ-Hmediated cell cycle arrest and to determine the influence of p53 status on the observed results, we performed quantitative real-time RT-PCR and Western blotting on all tested cell lines after 48 and $72 \mathrm{~h}$ of incubation with $10 \mu \mathrm{M}$ TQ-H-10 and TQ-H-11.

Compared to untreated controls, TQ-H-10 induced a significant increase in the mRNA levels of $\mathrm{p} 21^{\text {cip1/waf } 1}$ and a pronounced down-regulation of cyclin E in HCT116 cells (Fig. 5A). TQ-H-11 led only to a down-regulation of cyclin D after $72 \mathrm{~h}$, while all other parameters remained unchanged. In line with the view that $\mathrm{p} 21^{\text {cip } 1 / \text { wafl }}$ is a transcriptional target of p53 (11), no significant increase in p21 cip1/waf1 was observed in

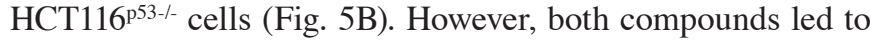
a suppression of cyclin D mRNA levels after $48 \mathrm{~h}$ (TQ-H-11) or $72 \mathrm{~h}$ (TQ-H-10). In HepG2 cells, which showed the greatest resistance to TQ-H treatments, no significant down-regulation of cell cycle-associated genes was observed (Fig. 5C). In this cell line, the increased expression of p53 and cyclins A, D and E was observed, which supports the findings regarding cell death and cell proliferation.

To confirm these results, quantitative Western blotting was performed (Fig. 6). In line with the previously described findings, the most resistant HepG2 cells showed a pronounced down-regulation of $\mathrm{p} 21^{\text {cip1/waf } 1}$ and $\mathrm{p} 53$, while cyclin levels were mostly unaffected at $48 \mathrm{~h}$. In the sensitive HCT116 cell line, we observed no increase in $\mathrm{p} 21^{\mathrm{cip} 1 / \text { wafl }}$ protein, but found a pronounced down-regulation of cyclins $\mathrm{A}$ and $\mathrm{E}$, particularly after $72 \mathrm{~h}$ of incubation with both TQ derivatives. At the protein level, HCT116 p53-- $^{5}$ cells also showed a downregulation of cyclins $\mathrm{A}$ and $\mathrm{E}$ after a 72-h treatment with $10 \mu \mathrm{M}$ TQ-H-11, while other parameters remained largely unaffected. Again, expression of p $21^{\text {cip1/waf } 1}$ was unchanged in these p53-deficient cells after treatment with either of the TQ compounds.
$48 \mathrm{~h}$

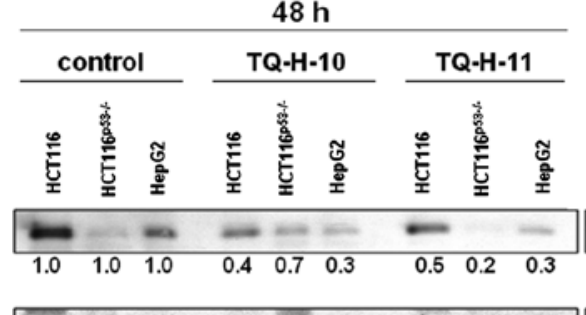

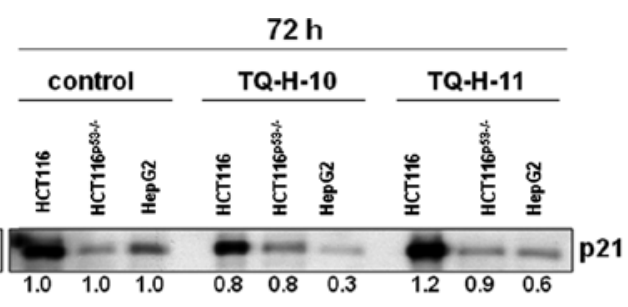
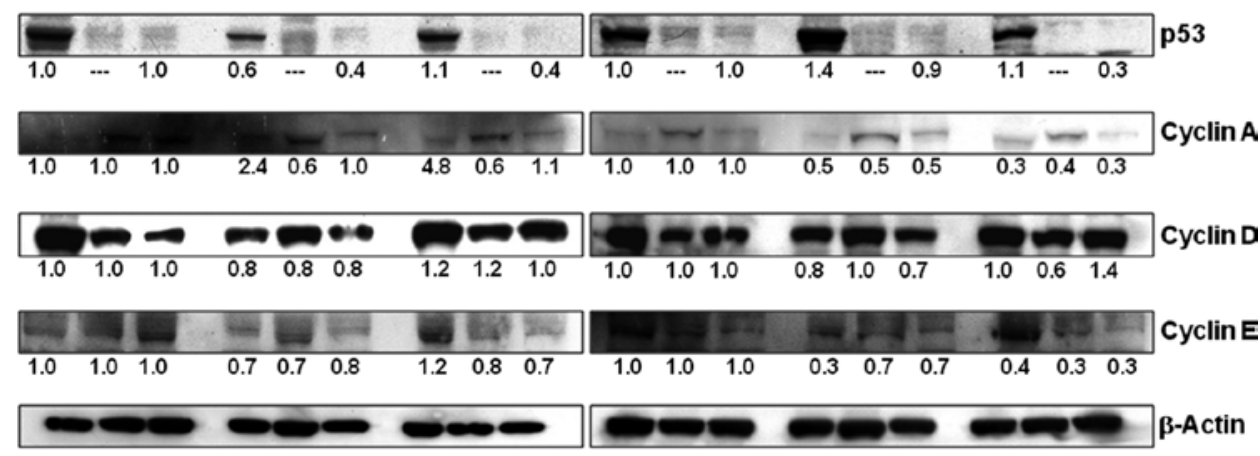

Figure 6. Western blot analysis of cell cycle-related genes. The depicted representative blots show changes in the protein expression of $\mathrm{p} 21^{\text {cip } 1 / \mathrm{waf} 1}$, p53 and cyclins A, D and E. Cells were incubated with $10 \mu \mathrm{M}$ TQ-H-10 or TQ-H-11. Bands were normalized to $\beta$-actin content and quantified relative to untreated controls using GelScan software. 


\section{Discussion}

Black seed (Nigella sativa) and its oil have traditionally been used in Arab and Mediterranean medicine for a variety of diseases, and have also become popular as food supplements in Western countries. Thymoquinone (TQ) was identified as the major active constituent of black seed essential oil (1), and has been demonstrated to exert anticancer effects in various models of human cancer $(2,3,10,12-14)$. Several molecular pathways of TQ activity in cancer cells have recently been described, for example, activation of caspases or p53-dependent mechanisms of cell growth control (4,15-17). Although these pre-clinical and experimental data provide encouraging evidence for a clinical application of TQ, its use in humans is limited due to its low chemical stability and poor solubility in aqueous solutions. We previously showed that the modification of TQ structure by attaching fatty acids enhances the pro-apoptotic and antiproliferative properties of the molecule (6). In the present study, we investigated the molecular effects associated with unsaturated (TQ-H-10) and saturated (TQ-H-11) fatty acid modifications of TQ in the human HCT116 colorectal cancer cell line and in a derivative lacking p53 (HCT116 ${ }^{\mathrm{p} 33-\mathrm{-}}$ ), as well as in the human HepG2 hepatocellular carcinoma cell line (p53 wild-type).

Our previous work showed that TQ effectively inhibits the proliferation of HCT116 cells at concentrations of $40 \mu \mathrm{M}$ or higher $(4,10)$. Modification of TQ with an unsaturated fatty acid enhanced this effect and resulted in significant growth inhibition, even at $10 \mu \mathrm{M}$, in p53-competent HCT116 cells (Fig. 2). This was associated with an increase in the $S / G_{2}$ cell population (Figs. 3 and 4). Notably, this effect was not observed in either HCT116 ${ }^{\text {p3-- }}$ or HepG2 cells, indicating a differential intracellular metabolism in liver and colon cell types as well as a dependency on p53 to inhibit cell cycle progression. Although previous studies have demonstrated a good apoptotic response to TQ in p53-deficient cells as well $(15,17)$, these results were obtained at higher concentrations of native TQ, which may also induce a non-specific cytotoxic reaction, for example, due to formation of oxidative stress which we demonstrated previously (6).

A molecular pathway analysis by quantitative RT-PCR and Western blotting revealed stable expression of the cell cycle inhibitor $\mathrm{p} 21^{\mathrm{cip} / \mathrm{waf} 1}$ in responsive HCT116 cells, but not in the other investigated cell lines (Figs. 5 and 6). Although an increase in p53 mRNA was observed in HepG2 cells, this up-regulation was not observed at the protein level, indicating a post-transcriptional processing of p53 mRNA (18). The observed growth inhibition and redistribution of cells to the $\mathrm{S} / \mathrm{G}_{2}$ phase was confirmed using PCR based on the observed strong down-regulation of mRNA for cyclins $\mathrm{D}$ and $\mathrm{E}$. Notably, TQ has previously been shown to induce $\mathrm{G}_{0} / \mathrm{G}_{1}$ arrest in various cancer cell lines $(12,16)$, suggesting a different interaction caused by the unsaturated fatty acid residue in TQ-H-10. Although this observation is in line with the known cell cycle inhibition properties of $\mathrm{p} 21^{\text {cip//wafl }}(19,20)$, the down-regulation, particularly of cyclin $\mathrm{E}$, which is crucial for progression from the $G_{1}$ to $S$ phase $(20,21)$, is in contrast to our results. However, recent reports suggest the possibility for cells to enter the $\mathrm{S}$ phase even when lacking CDK2/cyclin E complex activity $(19,20,22)$, and knockout mice for either cyclin $\mathrm{E}$ or
CDK2 also showed normal development (23). It is currently assumed that other cyclins can rescue the lack of CDK2/ cyclin $\mathrm{E}$ in this setting, and we observed a slight increase in cyclin A expression, which might be sufficient to promote cell cycle progression. As cyclin E overexpression is commonly observed in human malignancies and has also been proposed as a prognostic marker $(21,22,24-28)$, our findings indicate a beneficial effect, especially on cyclin E-positive tumors, by treatment with TQ-H derivatives. This effect is enhanced by covalent linkage to unsaturated fatty acid structures, resulting in extensive antiproliferative effects as described above.

\section{Acknowledgements}

The excellent technical assistant of Astrid Taut and Isabel Zeitträger is gratefully acknowledged.

\section{References}

1. Amin A, Gali-Muhtasib H, Ocker M and Schneider-Stock R: Overview of major classes of plant-derived anticancer drugs. Int J Biomed Sci 5: 1-11, 2009.

2. Worthen DR, Ghosheh OA and Crooks PA: The in vitro antitumor activity of some crude and purified components of blackseed, Nigella sativa L. Anticancer Res 18: 1527-1532, 1998.

3. Gali-Muhtasib H, Diab-Assaf M, Boltze C, et al: Thymoquinone extracted from black seed triggers apoptotic cell death in human colorectal cancer cells via a p53-dependent mechanism. Int J Oncol 25: 857-866, 2004.

4. Gali-Muhtasib H, Kuester D, Mawrin C, et al: Thymoquinone triggers inactivation of the stress response pathway sensor CHEK 1 and contributes to apoptosis in colorectal cancer cells. Cancer Res 68: 5609-5618, 2008.

5. Al-Ali A, Alkhawajah AA, Randhawa MA and Shaikh NA: Oral and intraperitoneal LD50 of thymoquinone, an active principle of Nigella sativa, in mice and rats. J Ayub Med Coll Abbottabad 20: 25-27, 2008.

6. Breyer S, Effenberger K and Schobert R: Effects of thymoquinone-fatty acid conjugates on cancer cells. ChemMedChem 4: 761-768, 2009.

7. Martin BT and Strebhardt K: Polo-like kinase 1: target and regulator of transcriptional control. Cell Cycle 5: 2881-2885, 2006.

8. Okamoto K, Neureiter D, Alinger B, et al: The dual EGF/VEGF receptor tyrosine kinase inhibitor AEE788 inhibits growth of human hepatocellular carcinoma xenografts in nude mice. Int $\mathbf{J}$ Oncol 33: 733-742, 2008.

9. Jabari S, Meissnitzer M, Quint K, et al: Cellular plasticity of trans- and dedifferentiation markers in human hepatoma cells in vitro and in vivo. Int J Oncol 35: 69-80, 2009.

10. Gali-Muhtasib H, Ocker M, Kuester D, et al: Thymoquinone reduces mouse colon tumor cell invasion and inhibits tumor growth in murine colon cancer models. J Cell Mol Med 12: 330-342, 2008.

11. Ocker M and Schneider-Stock R: Histone deacetylase inhibitors: signalling towards p21cip1/waf1. Int J Biochem Cell Biol 39: 1367-1374, 2007.

12. Shoieb AM, Elgayyar M, Dudrick PS, Bell JL and Tithof PK: In vitro inhibition of growth and induction of apoptosis in cancer cell lines by thymoquinone. Int J Oncol 22: 107-113, 2003.

13. Tan M, Norwood A, May M, Tucci M and Benghuzzi H: Effects of (-)epigallocatechin gallate and thymoquinone on proliferation of a PANC-1 cell line in culture. Biomed Sci Instrum 42: 363-371, 2006.

14. Edris AE: Anti-cancer properties of Nigella spp. essential oils and their major constituents, thymoquinone and beta-elemene. Curr Clin Pharmacol 4: 43-46, 2009.

15. El-Mahdy MA, Zhu Q, Wang QE, Wani G and Wani AA: Thymoquinone induces apoptosis through activation of caspase- 8 and mitochondrial events in p53-null myeloblastic leukemia HL-60 cells. Int J Cancer 117: 409-417, 2005. 
16. Gali-Muhtasib HU, Abou Kheir WG, Kheir LA, Darwiche N and Crooks PA: Molecular pathway for thymoquinone-induced cellcycle arrest and apoptosis in neoplastic keratinocytes. Anticancer Drugs 15: 389-399, 2004.

17. Roepke M, Diestel A, Bajbouj K, et al: Lack of p53 augments thymoquinone-induced apoptosis and caspase activation in human osteosarcoma cells. Cancer Biol Ther 6: 160-169, 2007.

18. Kruse JP and Gu W: Modes of p53 regulation. Cell 137: 609-622, 2009.

19. Sanchez I and Dynlacht BD: New insights into cyclins, CDKs and cell cycle control. Semin Cell Dev Biol 16: 311-321, 2005

20. Sherr CJ and Roberts JM: CDK inhibitors: positive and negative regulators of G1-phase progression. Genes Dev 13: 1501-1512, 1999.

21. Ekholm-Reed S, Mendez J, Tedesco D, Zetterberg A, Stillman B and Reed SI: Deregulation of cyclin E in human cells interferes with prereplication complex assembly. J Cell Biol 165: 789-800, 2004.

22. Hwang $\mathrm{HC}$ and Clurman BE: Cyclin $\mathrm{E}$ in normal and neoplastic cell cycles. Oncogene 24: 2776-2786, 2005.
23. Mendez J: Cell proliferation without cyclin E-CDK2. Cell 114: 398-399, 2003

24. Keck JM, Summers MK, Tedesco D, et al: Cyclin E overexpression impairs progression through mitosis by inhibiting APC(Cdh1). J Cell Biol 178: 371-385, 2007.

25. Schraml P, Bucher C, Bissig H, et al: Cyclin E overexpression and amplification in human tumours. J Pathol 200: 375-382, 2003.

26. Muller-Tidow C, Metzger R, Kugler K, et al: Cyclin E is the only cyclin-dependent kinase 2-associated cyclin that predicts metastasis and survival in early stage non-small cell lung cancer. Cancer Res 61: 647-653, 2001.

27. Erlanson $M$ and Landberg G: Prognostic implications of p27 and cyclin $\mathrm{E}$ protein contents in malignant lymphomas. Leuk Lymphoma 40: 461-470, 2001.

28. Wingate H, Puskas A, Duong M, et al: Low molecular weight cyclin $\mathrm{E}$ is specific in breast cancer and is associated with mechanisms of tumor progression. Cell Cycle 8: 1062-1068, 2009. 